$$
\begin{gathered}
\text { 부산 북항에서 } \mathrm{VTS} \text { 시스템에 의한 출입항 선박의 } \\
\text { 접이안 작업과정의 실시간 모니터링 } \\
\text { 이 대 재* }
\end{gathered}
$$

부경대학교 해양생산시스템관리학부

\title{
Real-time monitoring of berthing/deberthing operations process for entering/leaving vessels using VTS system in Busan northern harbor, Korea
}

\author{
Dae-Jae LEE* \\ Division of Marine Production System Management, Pukyong National University, Busan 608-737, Korea
}

The process of berthing/deberthing operations for entering/leaving vessels in Busan northern harbor was analyzed and evaluated by using an integrated VTS(vessel traffic service) system installed in the ship training center of Pukyong National University, Busan, Korea. The integrated VTS system used in this study was consisted of ARPA radar, ECDIS(electronic chart display and information system), backup(recording) system, CCTV(closed-circuit television) camera system, gyro-compass, differential GPS receiver, anemometer, AIS(automatic identification system), VHF(very high frequency) communication system, etc. The network of these systems was designed to communicate with each other automatically and to exchange the critical information about the course, speed, position and intended routes of other traffic vessels in the navigational channel and Busan northern harbor. To evaluate quantitatively the overall dynamic situation such as maneuvering motions for target vessel and its tugboats while in transit to and from the berth structure inside a harbor, all traffic information in Busan northern harbor was automatically acquired, displayed, evaluated and recorded. The results obtained in this study suggest that the real-time tracking information of traffic vessels acquired by using an integrated VTS system can be used as a useful reference data in evaluating and analyzing exactly the dynamic situation such as the collision between ship and berth structure, in the process of berthing/deberthing operations for entering/leaving vessels in the confined waters and harbor.

Key words : Berthing/deberthing operations, VTS system, Busan northern harbor, Real-time tracking

\footnotetext{
*Corresponding author: daejael@pknu.ac.kr, Tel: 82-51-629-5889, Fax:82-51-629-5885
} 


\section{서 론}

현재 부산 북항에서는 항계구역을 통항하는 선박이나 항만을 입 출항하는 선박을 대상으로 안전항행정보의 제 공과 호율적인 항만관제를 위해 VTS(vessel traffic service) 시스템이 설치 운 용되고 있다 이 VTS 센 터에서는 모든항행 선박 의 안전한 통항관제와 관련하여 각 선박의 레이 더 추적정보, $\mathrm{AIS}$ 수신정보, 위치보고정보, $\mathrm{VHF}$ 교신정보, $\mathrm{CCTV}$ 영상정보 및 기타 활용 가능한 모든 수집정보 등을 분석하여 항계구역 및 항만 에서 선박 상호간에 야기되는 조우, 교행 및 추 월상황 등을 실시간으로 평 가함으로써 선박의 충돌, 항만의 안전사고, 안전통항의 저해요인 등 을 미연에 제거 및 방지하기 위한 관제업무를 수행하고 있다. 그러나, 통항 척수의 증가에 따 른 가항수역의 감소, 항로와 안벽(부두) 사이의 선회공간 협소, 다수의 국지 적인 지역 에서 교차 통항이 빈번히 발생하는 등 통항의 흐름을 저해 하는 요인이 많아 항만관제 를 위한 선박 동적 거 동의 정량적인 평가, 분석이 절실하게 요구되고 있는 실정이다. 부산 북항을 출입항하는 선박의 도선 상황이나 안벽이나 부두시설 에 접이 안하는 상황과 같은 매우 협소한 영역내에서 전개되는 동적 상황에 대해서는 VTS 센터에서 이들 선박 에 대한 동적 거동정보의 정량적 수집, 평가, 분석 이 매우 제한적이기 때문에 안전한 도선관리 및 호율적인 접이안 작업 을 원활하게 지원 및 관리, 감시할 수 없는 문제가 있어 최근에는 선박접안 유도시스템, 도선예보시스템, 선박접이안 조종 시률레이터, HarborGuard(L - 3 communications, 2008) 등이 개발되어 활용되고 있다.

특히, 항만을 출입항하는 선박이 안벽이나 부 두 시설에 접이안하기 위해서는 예선의 사용이 필 요불가결 하다. 보통 예 선을 사용할 때에는 본 선이 저속으로 항행하는 관계로 외력의 영향을 크게 받는 문제로 인해 예선의 호율적인 배치 및 제어, 본선의 접이안 자세, 진출입 각도, 기상 및 해상상태 등을 적정하게 고려하지 않으면 접이
안 사고가 발생한다 이 때문에 강제 도선구에서 는 선 박이 부두시설에 접이안할 때, 도선사가 승 선하여 조력을 하지만 선박의 안전운항에 대한 선장의 책임은 면제되지 않는다. 즉, 접이안 사 고가 발생하면 선장의 과실 가능성에 무게를 두 고 조사가 이루어 지는 것이 일 반적 인 관례이다. 따라서, 항만을 출입항하는 선박의 통항 및 접이 안 상황에 대한 정 보를 보다 체 계적이고 정 량적 으로 수집, 평 가하여 접이안 작업에 대한 지원업 무를 한층강화하기 위한 보다 과학적인 정보수 집 및 관리시스템의 구축이 필 요하다(Thoresen, 2002; Oda et al., 2004; Yang et al., 2004; Yoon et al., 2007; Kitade et al., 2009).

본 연구에서는 이 문제에 주목하여 현재 부경 대학교 용당 캠퍼스에 구축한 VTS 훈련센터의 첨단정보수집시스템을 활용하여 부산 북항의 외항 방파제를 통과한 선 박이 부두에 접 안할 때 까지의 통항상황과 부두를 이안하여 출항하는 선 박의 동적거 동을 실 시간으로 모니터 링함으로 써 입 출항 선박과 예선의 모든 동적거 동을 정 량 적으로 수집, 평가 및 분석함으로써 만일에 있을 접이안사고의 발생시에 대한 각 선박의 책임한 계를 명확히 입증할 과학적인 정보를 제공하기 위한 방안을 모색하고자 하였다.

\section{재료 및 방법}

부경대학교 용당 캠퍼스 $\left(35^{\circ} 06^{\prime} .827 \mathrm{~N}, 129^{\circ}\right.$ $05^{\prime} .295 \mathrm{E}$ )에 설치, 운용되고 있는 통합항법 및 항만관제시스템을 이용하여 부산 북항을 입출 항하는 선 박의 통항상황과 부두(안벽)에 접이안 하는 선박과 예선의 동적거동을 정량적으로 평 가, 분석하였다. 이들 입출항 선박의 접이안 작업 상황을 실시간으로 추적하는데 사용한 VTS 시 스템 은 $\mathrm{ECDIS}(\mathrm{JAN}-901 \mathrm{M}, \mathrm{JRC}$ 및 FEA - 2807, Furuno), ARPA 레이더(JMA - 9923, JRC; FAR 2827, Furuno), AIS(AI3000, Euronav), CCTV (closed-circuit television), gyro compass(GRC - 50, Simrad), 풍향풍속계, DGPS (GP37, Furuno), 
VDR(Model3000, Transas), VHF 통신시스템 등 으로 구성하였는데, 그 시스템의 구성 계통도는 Fig. 1 과 같고, 이들 시스템으로부터 수집되는 모든 정보는 실시간으로 backup 시스템(PM3D, 마린전자)에 수록하였다.

$\mathrm{ARPA}$ 레이더에 의한 접이안 선박의 동적거동 추적

부산 북항에 입출항하는 선박이 부두에 접이 안할 때, 이들 접이안 선박과 접이안 작업을 보 조하는 예선의 동적거 동을 정 량적으로 평 가, 분 석 하기 위해 두 대의 선 박용 X - band 의 ARPA 레이더를사용하였고, 또한, 이들 ARPA 레이더 에 의한 영상신호와 모든 추적정보를 실시간으 로 수록하기 위해 2 개의 backup 시스템을 사용 하였다. 이들 backup 시스템에 탑재되어 있는 레 이더 표적 추적 모듈(radar target extractor(RTX)) 은 안테나에 수신되는 물표의 영상신호를 12 bit, $40 \mathrm{MHz}$ 로서 수치화하여 거리 및 방위방항 에 대한 echo memory map 을 생 성한 후, 수동 또 는 자동으로 물표의 추적정보를 추출하여 물표 의 영상신호와 함께 하드디스크에 저장하거나 외부의 접속장치에 출력하도록 설계하였다. 여 기에 사용한 두 ARPA 레이더의 송신출력은 모 두 $25 \mathrm{~kW}$ 이고, Furuno 레이더의 경우, 안테나의

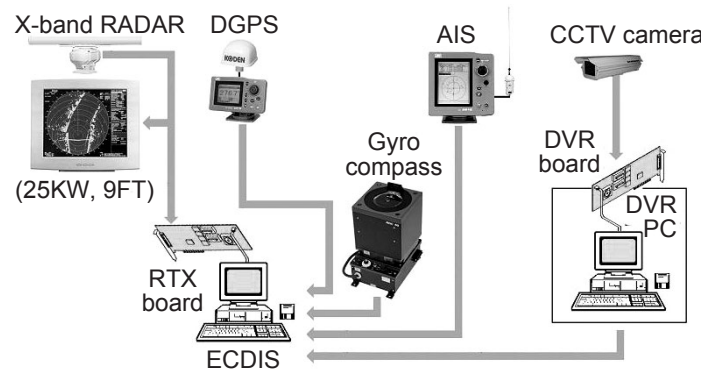

Fig. 1. Schematic configuration of a Vessel Traffic Service(VTS) system for the real-time monitoring of berthing/deberthing operations process to entering/ leaving vessels in Busan northern harbor, Korea. The VTS system used in this study is a fully integrated coastal surveillance system consisting of ARPA radar system, PC-based ECDIS, DGPS receiver, CCTV camera system, Gyrocompass, and AIS system.
수평 및 수직방향에 대 한 송신 지향각, 회 전수는 각각 $0.95^{\circ}, 20^{\circ}, 24 \mathrm{rpm}$ 이고, JRC 레 이더 는 각각 $0.8^{\circ}, 20^{\circ}$ 이 며, 회전수는 $26 \mathrm{rpm}$ 이다.

$\mathrm{AIS}$ 에 의한 접이안 선박의 자동 모니터링

부산 북항의 중앙 부두, 자성대 콘테이너 부 두, 신선대 콘테이너 부두에 접 이안하는 선 박과 그 접이안 작업을 보조하는 예선들로부터 수신 되는 AIS 의 동적정보를 실시간으로 수신함과 동시에 이 정보를 ARPA 레 이더 에 의한 추적 정 보와 함께 통합하여 해 당 선 박에 대 한 접 이안 상 황의 동적거동을 평가, 분석하였다. 이를 위해 해당 접이안 선박과 예선들로부터 송출되는 $\mathrm{AIS}$ 의 정적 및 동적정보, 즉, $\mathrm{RS} 232 \mathrm{C}$ protocol의 \$AIVDM 과 \$AIVDO sentence 를 ECDIS 의 ENC chart 화면상에서 모니터링하면서 각각의 sentence 정보를 실시간으로 수록하었다. 이들 sentence 에 는 MMSI( 해상이 동입 무식별) 번 호, $\mathrm{IMO}$ 번호, 호출부호, 선명, 선체장, 폭, 선박의 종류, 측위안테나 위치와 같은 정적인 정보와, 선 박의 위치, GMT, 대지침로, 대지속도, 선수방 위, 회두율(ROT), 항행 status 와 같은 동적인 정 보, 또한, 흘수, 적 재물, 목적지, 도착예정시간과 같은 항행정보가 실려 있는 데, 여기서는 이들 정보 중에서 특히, 위치, 침로, 속력, 거리 및 방 위의 변화 등에 주목하여 분석을 수행하였다.

$\mathrm{CCTV}$ 카메라 시스템에 의한 접이안 선박 영상 의 모니터링

부두 접이안 선박의 동적거동을 직 접 시각적 으로 모니터링하기 위해 최저 조도 $0.00071 \mathrm{ux}$ 의 고해상도 카메리(SDN - 550, 삼성테크원) 및 근 거리와 장거리 물표의 탐색이 모두 가능하도록 초점거리를 $12 \mathrm{~mm}$ 에서 $660 \mathrm{~mm}$ 까지 가변이 가능 한 전 동렌 즈(H55ZME - F, PENTAX) 로써 CCTV 카메라 시스템을 구성하고, 방수형 하우징 속에 $\mathrm{CCTV}$ 카메라 시스템을 설치함과 아울러 해풍, 염 분, 강우에 의한 이물질이 하우징 의 투시창에 
부착됨으로서 야기되는 영상의 선명도 저하를 방지하기 위해 투시창에 와이퍼를 설치하여 사 용하였다. 또한, 동계에 기온의 급강하에 따른 $\mathrm{CCTV}$ 시스템의 성능저하를 방지하기 위해 전 열 시스템을 장착하여 하우징 내 부온도를 일 정 하게 유지토록 하였다. 본 연구에서는 먼저 두 대의 ARPA 레이더를 사용하여 연구대상으로 설정한 접이안 선박과 이를 보조하는 예선을 자 동모드로써 추적함과 동시에 AIS 시스템에 수 신되는 해당 선박들로부터의 동적정보를 두 대 의 $\mathrm{ECDIS}$ 시스템의 $\mathrm{ENC}$ 화면상에 서로 중첩시 켜 모니터링하었다. 또한, 이들 모든 추적 정보는 두 대의 backup 시스템으로 전 송하여 수록함과 동시에 추적중인 접이안 선박과 예선에 대한 ARPA 레이더의 \$RATTM sentence 와 AIS 의 \$AIVDM sentence로부터 추적물표의 거리, 방위 정보 등을 추출한 후, 이 정보를 토대로 $\mathrm{CCTV}$ 시 스템의 pan/tilt driver 및 controller(KBD3000A, Pelco)를 수동으로 조작하여 CCTV 카메 라의 탐 색방향, 즉, 방위각과 고도각을 제어 함으로써 해 당 선박에 대한 동영상을 실시간으로 모니터링 하였다. 이들 모니터링 선박에 대한 동영상 신호 는 두 대의 backup 시스템에 탑재된 ECDIS 의 $\mathrm{ENC}$ 화면상에 ARPA 레이더 영상, AIS 표적 심 볼과 함께 표시함과 동시에 ECDIS 시스템 및 전 용 DVR 시스템의 harddisk 에 각각 독립 적으로 수 록하였다. 따라서, 추적 중인 접이안 선박에서 예 기치 못한 선박사고가 발생하더라도 ECDIS 시 스템에 수록된 모든 정보를 수록당시 의 시각으 로 설정 하여 재생하면 ARPA 레이더, AIS, CCTV 카메라 시스템 등에 의한 모든 정보가 원래 의 상 태로 재현됨으로써 모든 사고의 원인을 명확하 게 규명할 수 있는 법적 자로 로 활용할 수 있다.

\section{결과 및 고찰}

입항 선박에 대한 접안 작업상황의 실시간모니터링

입항 선박이 부산 북항 교통관제구역 내로 진 입할 때, 당해 선 박은 선 명, 호출부호, 통과위치,
침로 및 속력 등에 대한 직입 보고를 먼저 수행 하고, 항계구역에 진입해서부터는 접안장소 및 접안시각 등을 추가로 보고하게 된다. 이 때 부 터 VTS 센터에서는 $\mathrm{ECDIS}$ 의 $\mathrm{ENC}$ 화면상에서 해당선박에 대한ARPA 레이더 영상과 AIS 정보 의 모니터링 및 $\mathrm{VHF}$ 통신망에 의한 정보고환 등 을 통해 해당 선박을 식별한 후, 도선사가 승선 하면 입항관제가 시작되어 예정된 선석에 접안 이 완료되면 입항관제를 종료하게 된다.

이 때, 항만으로 진입하는 대부분의 입항선박 은 지정된 안벽이나 부두에 접안시 선 박의 접 안 조종을 원 횔하게 수행하기 위해 예선을 사용하 게 되는데, 예선의 조력을 받아 부두나 안벽에 접근할 때, 본선이 저속으로 움직이는 관계로 외 력 의 영항을 크게 받는 경 우에는 선 박이 안벽의 구조물이나 부두의 하역시 설(하역 크레인)과 충 돌하는 예기치 못한 선 박안전사고가 빈번하게 발생하고 있는 실정이 다: 이와 같은 선 박의 접안 사고가 발생할 때, 이해 당사자 사이에 제기되는 책임소재 유무를 명확하게 평가, 분석하기 위해 서는 매우 국지적인 수역 내에서 발생하는 이들

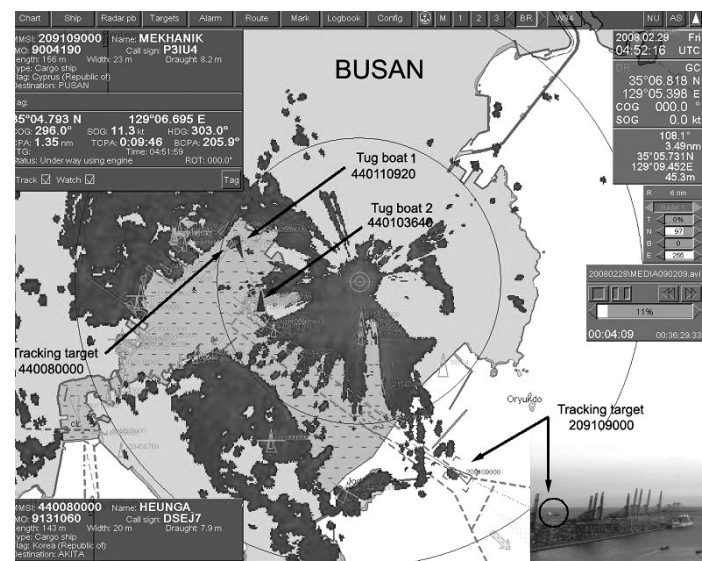

Fig. 2. An example of real-time monitoring of the berthing/deberthing situation for entering/leaving vessels in Busan northern harbor, Korea. The tracked information of AIS targets including two tugboats is displayed on the ENC of a PC-based ECDIS with ARPA radar image and CCTV camera image. This ECDIS information is used to evaluate the change in the movement of all selected vessels. 
선박의 동적거 동을 실시간으로, 또한 정량적으 로 모니터링 할 필요가 있다. 이를 위해 본 연구 에서는 부산 북항에서 VTS 관제구역을 경우하 여 외항 방파제를 통과한 후, 내항의 접안부두 (중앙부두) 를 향해 이동하는 조사대상 선박 (MMSI 209109000)의 동적거 동을 ARPA 레이더, $\mathrm{AIS}, \mathrm{CCTV}$ 카메라 시스템 등을 사용하여 일 정 시간간격으로 추적 및 분석하였는데, 그 결과는 Fig. 2 와 같다. Fig. 2 에서는 자성대 콘테이너 터 미 널에서 출항하는 선박(MMSI440080000)과 이 선박의 이안작업을 지 원하고 있는 예선(MMSI 440110920), 또한, 감만 시민부두에서 대기중인 다른 한 척의 예선(MMSI 440103640)에 대한 례 이더 영상과 AIS 위치도 함께 나타내었다. 여기 서 ARPA 레이더 시스템을 사용하여 수록한 레 이더 영상은 $\mathrm{AIS}$ 에 의한 동적정보와 함께 $\mathrm{ECDIS}$ 시스템의 전자해도 화면상에 서로 중첩 시켜 나타내었다. Fig. 2 에서 ARPA 레이더 및 $\mathrm{AIS}$ 에 의해 동시 추적중인 입항 및 출항 선박의 정적 및 동적정보, 즉, $\mathrm{MMSI}$, 선명, $\mathrm{IMO}$ 번호, call sign, 선박제원, 위치, $\mathrm{COG}, \mathrm{SOG}, \mathrm{HDG}$, $\mathrm{CPA}, \mathrm{TCPA}$ 등은 $\mathrm{ENC}$ 화면의 좌측 상단부와 하 단부에 각각나타내 었고, 외항 방파제 를 통해 진 입하고 있는 입항선의 CCTV 카메라 영상은 $\mathrm{ENC}$ 화면의 우측 하단부에 함께 나타내었다. 또 한, Fig. 2 에서는 이들 모든 선박에 대한 ARPA 레이더, AIS 및 CCTV 카메라 시스템에 의한 각 종 정보의 시간지연을 최소화시키기 위해 각 시 스템으로부터 수집되는 정보에 세 계시(UTC)의 time tag 를 붙여 harddisk 에 수록하고, 이들 데이 터를 재 생하면서 정 량적 인 분석을 행 한 결 과이 다. 국토해양부에서는 AIS 로부터 발신되는 모 든 선박의 동적정보를 전자해도화면 에 표시하 는 선박모니터링시스템을 구축하여 운영하고 있고, 이 시스템으로부터 수집되는 선박운항정 보를 해양경찰청, 수산업협동조합 중앙회(어 선), 한국해운조합(여 객선) 등의 관계기 관에 제 공하고 있다. 그러나, Fig. 2 에서 알 수 있는 바와
같이 선박의 통항상태가 매우 복잡하고, 입 출항 선 박의 접이안이 빈번하게 이루어지 는 내 항에 있어서는 선박이 미속으로 거동하는 관계로 $\mathrm{AIS}$ 의 동적정보 중에서 특히, $\mathrm{COG}, \mathrm{SOG}$ 등에 급격한 변동이 발생하여 추적선박의 동적거동 을 정 량적으로 파악하는 것이 매우 어렵다. 이 때 문에 AIS 정보만을 받아 선박의 입 출항 및 접 이안시에 대한 안전사고의 예방과 처리, 또한, 내항에서 야기되 는 각종의 위험상황을 신속하 고 호율적으로 파악하여 적절한 조치를 취하는 데 에는 많은 제 약이 수반되 기 때문에 Fig. 2 에서 와 같이 AIS 정보뿐만 아니라 레이더의 image 정보 및 $\mathrm{CCTV}$ 카메라의 영상정보까지 도 실시 간으로 제 공할 필요가 있다고 판단된 다.

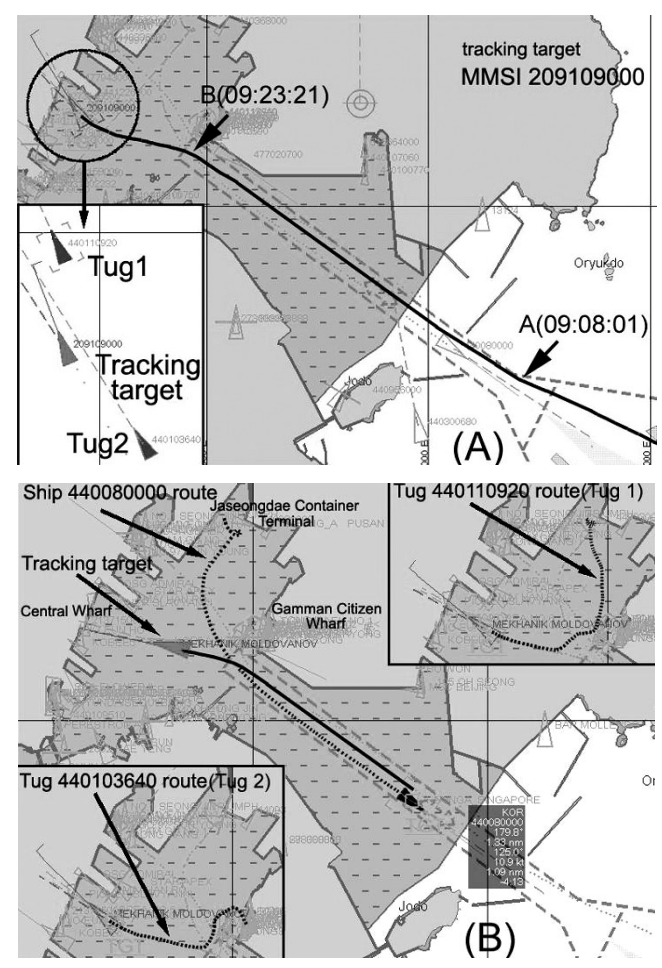

Fig. 3. (A) Real-time monitoring of berthing operation process for the entering vessel(MMSI209109000) being approached toward the pier to be berthed along the entering waterway. (B) Running routes of leaving vessel(MMSI440080000) and two tugboats(MMSI 440110920/440103640) in Busan northern harbor, Korea. 
현재, 부산의 조도 VTS 센터에서는 관제구역 으로 진입하는 모든 선박의 호율적인 통항관리 를 위해 ARPA radar, AIS, VHF 통신망 등을 이 용하여 선박 상호간의 조우, 고행 및 추월상태 등을 실시간으로 감시하고있다. 그려나, 관제선 박이 내항으로 진입중이거나 이미 진입하여 지 정된 선석으로 이동할 때 에는 항내의 각종 구조 물에 의해 레이더 전 퐈가 차단되 거나 또는 다중 산란에 의한 거짓상(false echo) 등이 발생하여 ARPA radar 정 보만으로는 관제선 박의 지속적인 위치추적이 어렵기 때문에 현 실적으로는 AIS 와 같은 $\mathrm{VHF}$ 통신망에 의한 정보에 의존하여 관제 업무를 수행하는 경우가 많다. 특히, Fig. 2 에서 감만 콘테이너 터미널 부두와 신선대 콘테이너 터미널 부두의 경우에는 이곳에 설치, 운용되고 있는 다수의 대형 크레인 에 의해 유발되는 거짓 상들이 내항의 항로에 까지 신장되어 나타나고 있어 이 수역을 통항하는 선 박의 식별이 어 렵다. 이 때문에 본 연구에서는 $\mathrm{AIS}$ 의 동적정보만을 이용하여 입 출항 선박의 접이안 작업과정을 분 석 하였 는데, 그 결 과는 Fig. 3 과 같다.

Fig. 3(A)는 Fig. 2 에 서 입 항 선 (MMSI 209109000)이 관제구역에 진입하여 외항 방파 제를 통과한 후, 지정선석인 중앙부두로 접안하 고 있는 상황을 모니터 링한 결 과이고, Fig. 3(B) 는 자성대 콘테이너 터미널 부두에서 한 척의 예 선(MMSI 440110920)의 지원을 받아 이안하고 있는 출항선(MMSI440080000) 과 Fig. 3(A)의 입 항선의 접안을 지원하기 위해 감만 시민부두와 자성대 콘테이너 터미널 부두로부터 이동하고 있는 두 척의 예선(MMSI 440103640, MMSI 440110920)에 대한 AIS 의 항주계 적을 나타낸 결 과이다.

Fig. 3 의 (A)와 (B)에서 알 수 있는 바와 같이 입출항 선박과 이들 선박의 접이안을 지원하고. 있는 예선들이 약 $3 \mathrm{knots}$ 이상의 속력으로 움직 이는 경우에 있어서는 AIS 에 수신되는 동적 데 이터의 갱신이 비교적 정 상적으로 이루어져 이
들 선박의 동적거 동을 실시간으로 추적할 수 있 었으나, 이동속력이 $3 \mathrm{knots}$ 보다 저속인 경 우에 있어서는 동적 데이터가 갱신되지 않아 위치추 적에 많은 문제가 발생하였다.

한편, Fig. 3(A)에서 북항 외항의 항계수역에 설정된 통항분리대의 안전수역을 통과하여 입 항항로를 따라 내항으로 진입하는 관제선박의 선수방위(HDT, $\mathrm{COG}$ )와 ROT 의 변동특성을 실 시간으로 추적하여 나타낸 결 과는 Fig. 4 와 같 다. 관제 선박이 진침로 $294^{\circ}$, 속력 $11.2 \mathrm{knots}$ 로 통항분리대의 안전수역으로 접 근하여 09:08:01 에 $\mathrm{A}$ 점을 통과하는 순간, 입항 항로상으로의 진 입을 위한 침로 $305^{\circ}$ 를 유지하기 위해 타각을 우 현으로 변경함으로써 $\mathrm{ROT}$ 값이 $0 \% \mathrm{~min}$ 부근에 서 $+23.6 \% \mathrm{~min}$ 까지 변 동하였고, 그 후, 입항침로 가 설정된 시점부터는 타각이 다시 복귀됨으로 써 $\mathrm{ROT}$ 가 $0 \% \mathrm{~min}$ 부근으로 수렴하고 있음을 알 수 있다 관제선박은 이 상태로 속력 $11.6 \mathrm{knots}$ 로
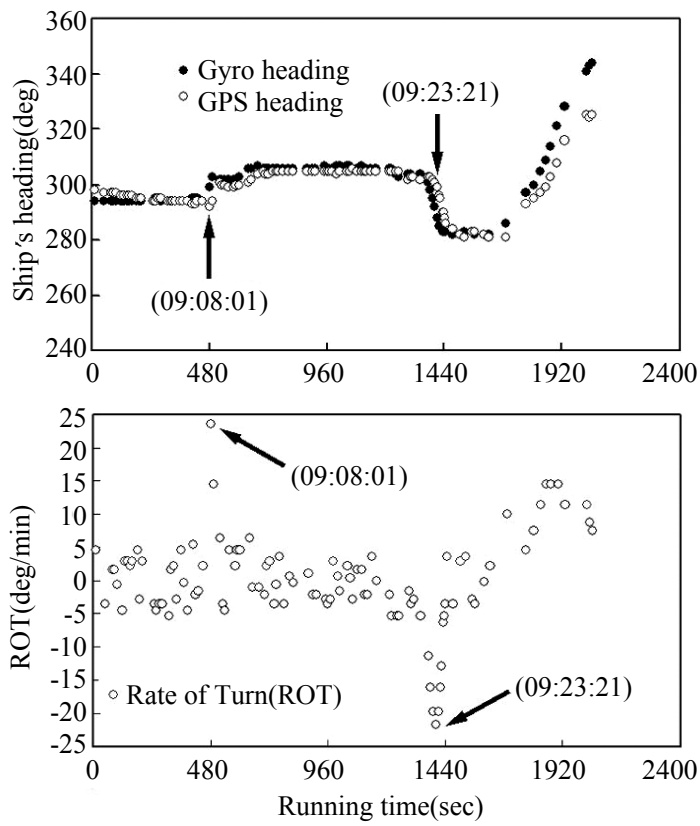

Fig. 4. Relationship between ship's heading and ROT variations for the entering vessel being approached toward the pier to be berthed along the entering waterway of Busan northern harbor. 
계속 항주하여 내항 방퐈제를 통과한 직후인 09:23:21 에 B 지점을 통과하는 순간, 중앙부두 지정선석으로 접근하기 위한 침로 $283^{\circ}$ 를 유지 하기 위해 좌현으로 타각을 변경함으로써 ROT 값이 $0 \% \mathrm{~min}$ 부근에서 $-21.6 \% \mathrm{~min}$ 까지 변동하 고 있음을 알 수 있다 그 후, 중앙부두에 접근해 서는 지정선석에 좌현으로 접 안하기 위한 접안 조종을 수행함에 따라ROT 값이 $0-(+) 15^{\circ}$ 범 위 에서 불규칙하게 변 동하는 거동특성을 매우 정 량적이면서도 실시간으로 추적 및 모니터링 할 수 있었다.

현재, 우리나라에 서는 선박설비규정 제 107 조 에 의거 충톤수 50,000 톤 이상의 선 박에 는 회두 각속도계, 즉 선회율지시기(ROT 센서)를 의무 적으로 설치하도록 규정하고 있고, 이 지시기는 $30 \% \mathrm{~min}$ 이상의 선회율 을 표시할 수 있어야 한 다. Fig. 3(A) 의 조사대상선 박(MMSI 209109000)
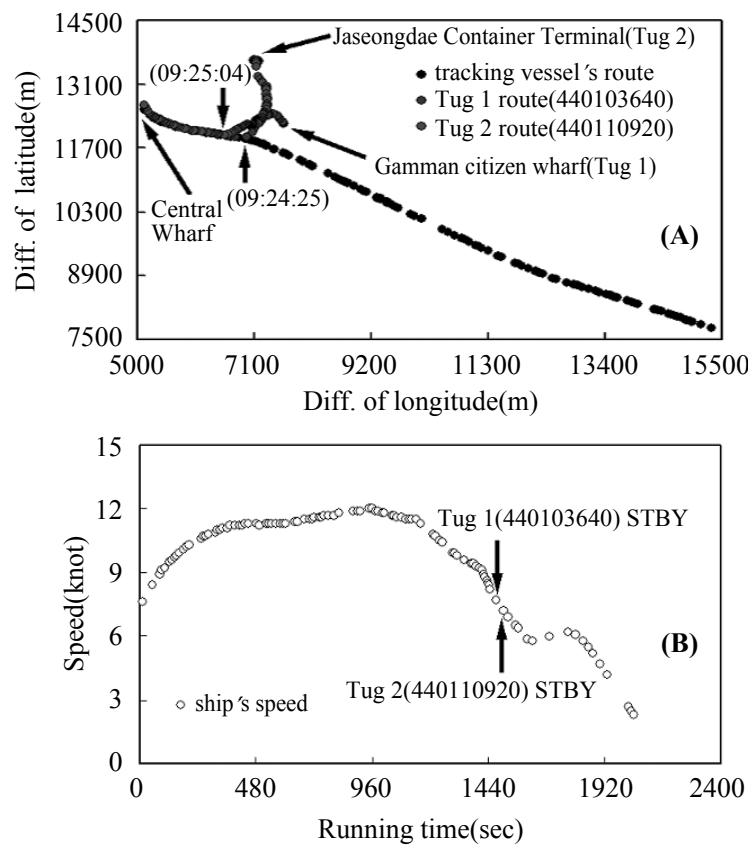

에는 ROT 센서가 탑재되어 있어 일정시간 간격 으로 \$TIROT sentence 로부터 $\operatorname{ROT}(\% / \mathrm{min})$ 정보 를 읻을 수 있었다. Fig. 3 의 (A)와 (B)에서 입항 선 박이 지정선석인 중앙부두 인근수역으로 진 입하면 접안 조종을 지 원하기 위한 두 척의 예선 이 우현 선수측 및 선미측으로 접근하는데, 이 때, 입 항선 과 예선의 동적거 동을 정 량적 으로 분 석, 고 찰한 결 과는 Fig. 5 와 같다.

Fig. 5 에서 예 선 1(MMSI440103640)은 감만시 민부두에 서 이동하여 09 시 24 분 25 초에 $35^{\circ}$ $06^{\prime} .434 \mathrm{~N}, 129^{\circ} 03^{\prime} .681 \mathrm{E}$ 의 위치에서 입항선 의 우현 선수측으로 docking 하였고, 예선 2(MMSI 440110920)는 자성대 콘테이너 터미널 부두에서 이 동하여 09 시 25 분 04 초에 $35^{\circ} 06^{\prime} .454 \mathrm{~N}, 129^{\circ}$ $03^{\prime} .570 \mathrm{E}$ 의 위치에서 입항선의 우현 선미측으 로 docking 하였음을 알 수 있었다. 이 때, 예선 1 과 예선 2 가 중앙부두의 지정선석으로 접안을
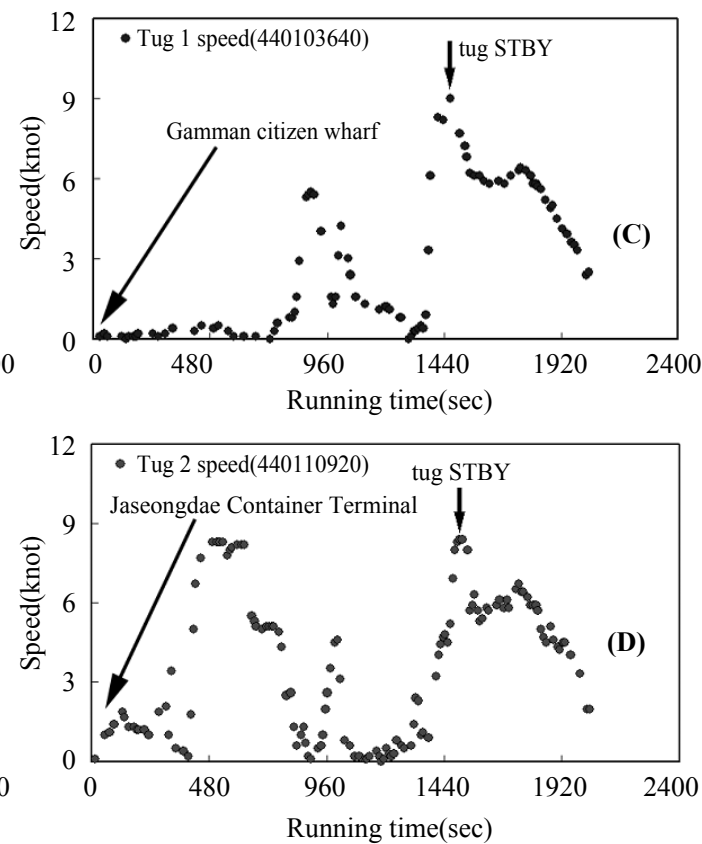

Fig. 5. Tracked results of maneuvering motions for a target ship(MMSI 209109000) approaching to the central wharf in order to get alongside to her berth in Busan northern harbour. The maneuvering motions for a tugboat(MMSI 440110920) approaching toward the entering vessel from Jaseongdae container terminal and a tugboat(MMSI 440103640) approaching toward the entering vessel from Gamman citizen wharf were simultaneously tracked, respectively. 
시도하는 선박에 docking 하였을 때의 입항선의 속력은 각각 $7.7 \mathrm{knots}, 7.2 \mathrm{knots}$ 이었고, 그 때의 예선 1 과 예 선 2 가 docking 하기 위해 이 동한 최 대속력 은 각각 9.0 knots 와 8.4 knots 이 었다. 이와 같이 입항선 및 예선의 선속이 비고적 큰 경우에 있어서는 $\mathrm{AIS}$ 의 동적정보를 연속적으로 추적함 으로서 이들 선박의 조종 및 거 동특성을 정 량적 으로 평가, 분석할 수 있음을 알 수 있었다.

출항 선박에 대한이안 작업상황의 실시간 모니 터링

출항선박에 대한 이안작업 상황을 정 량적으 로 평 가, 분석하기 위해Fig. 2 및 Fig. 3(B)에서와 같이 신선대 콘테이너 터미널 부두에 서 출항하 는 선박(MMSI 440080000)을 대상으로 ARPA radar 의 영상정보와 AIS 에 의 한 동적거 동정 보를 상호 연관시켜 출항선과 이안작입을 보조하는 예 선(MMSI440110920)의 동적거동을 실시간으 로 추적, 고찰하였는데, 먼저 출항선과 예선에
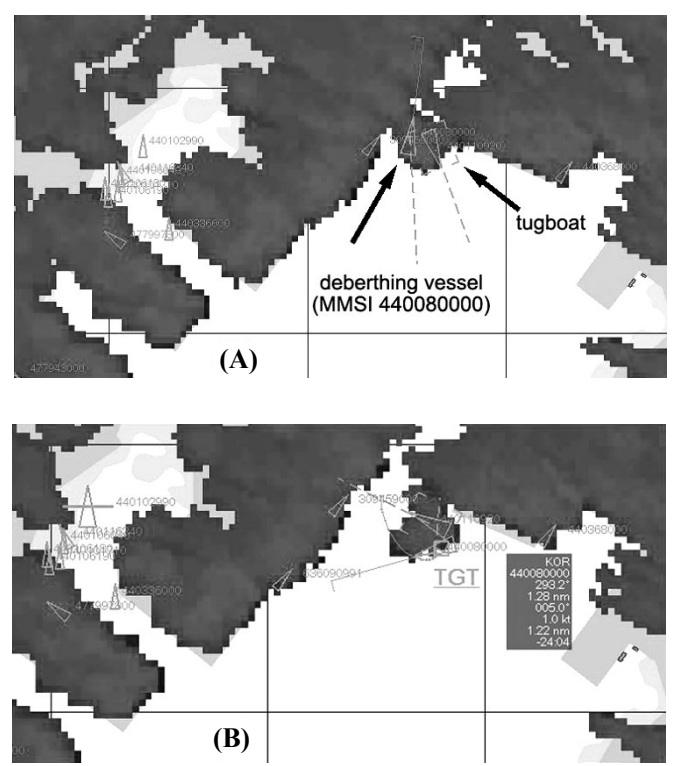

Fig. 6. AIS data and ARPA radar images for the deberthing vessel(MMSI 440080000) and its tugboat(MMSI 440110920) towing the vessel that is berthed port side alongside to the $\mathrm{NW}$ face of the Jaseongdae container terminal out of the pier.
대한ARPA 레이더 영상과 AIS 정보를 중첩시켜 분석한 결 과는 Fig. 6 과 같다. Fig. 6 에서 알 수 있 는 바와 같이 출항선 과 예선의 ARPA 레이더 영 상은 거리 및 방위분해능의 관계로 분리되어 식 별되지 않으나, 각 선박의 AIS 위치는 서로 분리 되어 표시 되고 있다. 또한, AIS 위치 에 대한 선수 방위 및 이동계적을 분석하면 현재 이들 선박의 동적 거동을 평가할 수 있지 만, $\mathrm{AIS}$ 에 의한 $\mathrm{COG}$, $\mathrm{SOG}$ 는 GPS 위치(궤적)의 변화로부터 산출되는 정보이기 때문에 gyro compass 에 의한 선수방위 (HDT) 정보를 얻을 수 없고, 선속이 미속일 경우 에는 동적거동을 정확하게 파악할 수 없다는 문 제가 있음을 알 수 있었다. 또한, Fig. 6 의 ARPA 레이더 및 AIS 정보를 시각적으로 관찰하는 것 만으로서는 출항선과 이안작업 을 보조하는 예선 의 동적거동을 동시에 정량적으로 평가, 분석하 는 것이 어렵다. 따라서, 이들 두 선박의 AIS 동 적정보와ARPA 레이더 영상의 이동궤적 정보로 부터 추출된 데이터를 토대로 각 선박의 이동궤 적을 추적 및 도시 한 결과는 Fig. 7 과같다.

Fig. 7 에서 이안작업은 예 선이 출항선 에 연결 된 曳索을 당기는 $\mathrm{a}$ 지점으로부터 시작되는데, 이안이 시작된 후에는 출항선과 예선의 위치궤 적의 이동패턴이 매우 유사하게 전 개되어 출항

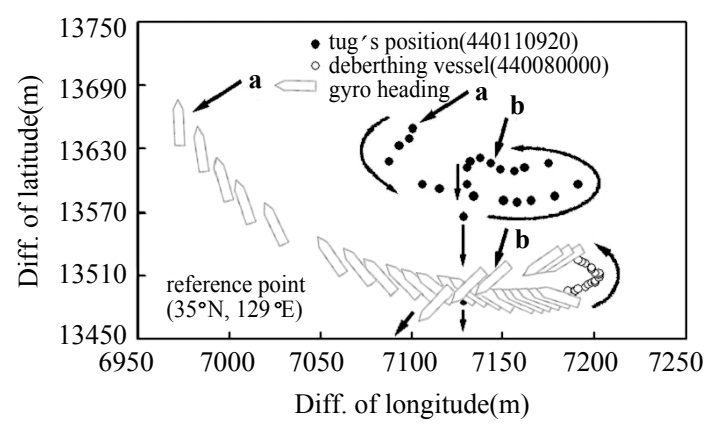

Fig. 7. Changes in the maneuvering motion tracks for the deberthing vessel being towed by one tugboat from the berth and its tugboat during the deberthing operation process. The deberthing vessel being assisted out of the pier by one tugboat from central wharf and its tugboat are shown with ship mark(or white circle) and black circle, respectively. 
선은 전적으로 예선에 의해 조종되고 있음을 알 수 있고, $\mathrm{b}$ 점을 통과한 후 부터는 출항선이 자력 으로 기동하여 안벽을 이탈해 가고 있음을 알 수 있다. 여기서 $\mathrm{AIS}$ 의 동적정보 만에 의 존하는 경 우에는 선속이 미속일 때, 동적정보의 갱신간격 이 매우 길고, 불규칙하게 수신되므로, 이 경우 에는 ARPA 레이더 영상의 계적정보를 토대로 AIS 데이터를 보완함으로서 연속적인 추적이 가능함을 알 수 있었다.

Fig. 7 에 서 출항선 박은 ROT 센서를 탑재하고 있지 않은 관계로 정확한 ROT 정보는 얻을 수 없었지만, gyro compass 로부터 수신되는 HDT 정 보로부터 산출된 개략적인 ROT 정보는 파악할 수 있었다. 즉, ROT 센서가 접속되지 않은 경우, AIS 에서 는 HDT message 에 포함되어 있는 진침 로 정보로부터 ROT 정보를 산출하여 출력하는 데, 이 때, 그 출력 데이터는 ROT $>+10^{\circ} / \mathrm{min}$ 보 다 큰 경우에는 $+720 \% \mathrm{~min}$ 를, $\mathrm{ROT}<-10 \% \mathrm{~min}$ 인 경우에는 $-720 \% \mathrm{~min}$ 를, 또한 그 이외 의 경우 에 는 $0 \% \mathrm{~min}$ 를 출력하여 선박의 선회방향에 대 한 대략적인 정 보만을 제 공한다. 이 때, + 는 우 선회를, 또한 - 는 좌선회를 의미한다(Nauticast, 2004). 또한, Fig. 7 에서 관제대상선박이 예선에 이끌려 이안될 때, 이안(출항) 선박의 $\mathrm{COG}$ 와 $\mathrm{SOG}$ 정보는 GPS 위치의 지리적 변화로부터 산 출된 정보이므로, 이 정보를 수신하는 $\mathrm{AIS}$ 의 COG 값은 gyro compass 에 의 한 선 수방위(HDT) 와 일치하지 않는데. 이 문제를 분석, 고찰한 결 과는 Fig. 8 과 같다. Fig. 8 에 서 예 선에 의해 이안 되고 있는 출항선의 이동속력은 $0.5-3.0 \mathrm{knots}$ 범위이었고, 이 때, $\mathrm{COG}$ 와HDT 사이에는 큰 차 이가 있음을 알 수 있다. 그러나, 출항선이 자력 으로 항주를 시작하여 선속이 약 $3 \mathrm{knots}$ 이상으 로 증가하면서부터 $\mathrm{COG}$ 는 $\mathrm{HDT}$ 와 거의 일치하 는 경항을 나타내었다. 특히, Fig. 7 에서와 같이 선박이 하역작업을 종로하고 도선사가 승선한 후, 선석(부두)에서 이안할 때, 이안선박의 거 동 이 저속인 관계로 외력의 영향을 크게 받을 우려

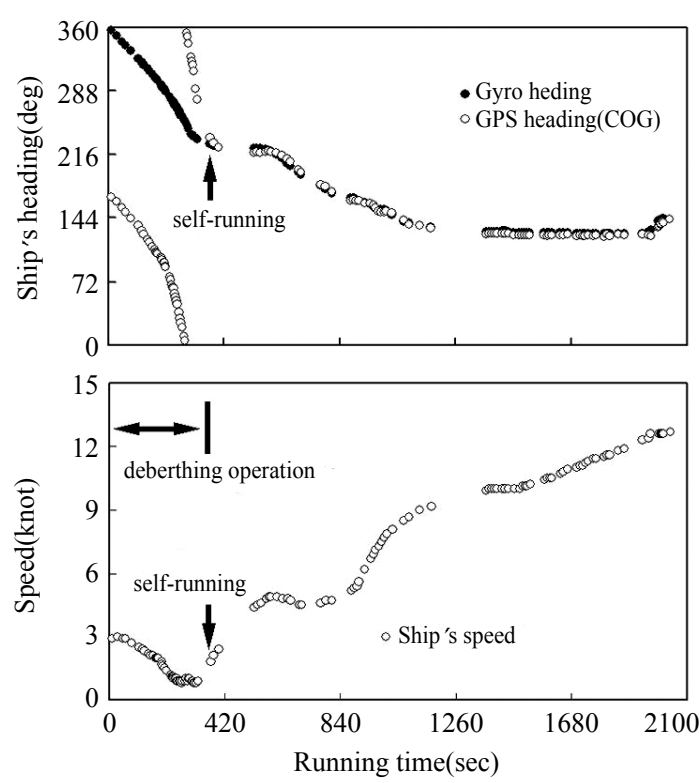

Fig. 8. Variations in ship's heading and speed of the deberthing vessel being towed by one tugboat from the berth during the deberthing operation process.

가 있으므로 이안 선박에 대한 동적거 동의 추적 에 세심한 주의 가 요구된다. 보통 선석에서 이안 시에는 본선이 개략적인 이안 상황을 VTS 센터 에 통보하는 것으로부터 출항관제가 시작되 고, 이 때부터 ECDIS 의 ENC 화면상에서 해당선박 에 대한 ARPA 레이더의 추적, AIS 정보의 모니 터링 등이 수행된다. 또한, 이와 동시 에 VHF 통 신망을 통해 해당 선박과의 직접 적인 정보교환 을 유지하면서, 해당 선박에 대한 관제업무는 위 치 보고선을 통과하는 순간까지 지속된다. 이 과 정에서 관제선박을 연속적으로 추적 및 식별해 야 하지 만, ARPA 레이 더 식별 의 경우에는 Fig. 2 에서 와 같이 각종 항만구조물, 특히, 대형 의 크레 인 시설 등에 의 한 shadow zone 의 발생 하거 나 다 중산란에 기인하여 관제선박의 영상이 masking 되는 현상이 빈번하게 발생하여 항만 내에서의 radar 영상의 추적 에는 많은 어려 움이 있다. 이 경 우에 는 AIS 모니터링에 통한 관제 선박의 추적이 수행되지만, 통항선박이 폭주하는 경우에는 식 별선박과 기타 인근선박 사이의 근접 성에 기인 
하는 AIS target 의 swapping 현상이 초래되는 경 우가 있기 때문에 관제 상의 오판을 미연에 방지 하기 위한 세심한주의가 요구된다.

ARPA 레이더, AIS 및 CCTV 카메라 시스템에 의한 모니터링 정보의 통합분석

최근 우리나라 주요 항만을 출입항하는 선박 의 통항량이 대 폭 증가하여 각 항만에 대 한 가항 수역의 점유비율이 점차 감소함으로써 항로와 안벽(부두) 사이의 선회공간이 협소해 진 관계 로 입 출항 선박 상호간의 충돌, 또한 접이안 선 박이 하역 crane 시설과 충돌하는 사고 둥이 빈 번하게 발생하고 있는 데, 이에 대한 정 량적 분 석을 위해 신선대 터미널 부두에 접안, 또는 이 안하는 선박을 대상으로 AIS, CCTV 카메라 및 $\mathrm{ARPA}$ 레이더 정보 등을 상호 관련시켜 비교 분 석한 결 과는 Fig. 9 및 Fig 10 과 같다. Fig. 9는 입 항선과 예선의 동적거 동을 AIS 와 CCTV 카메라 영상 정보를 서로 관련시켜 분석한 결 과이고, 또 한, Fig. 10은 출항선 과 예선의 동적거 동을 $\mathrm{AIS}$, $\mathrm{CCTV}$ 카메라 및 ARPA 레이더 정보를 상호 관 련시켜 분석한 결 과이다.

먼저, Fig. 9 에서 입항선(MMSI 525019103)에 대

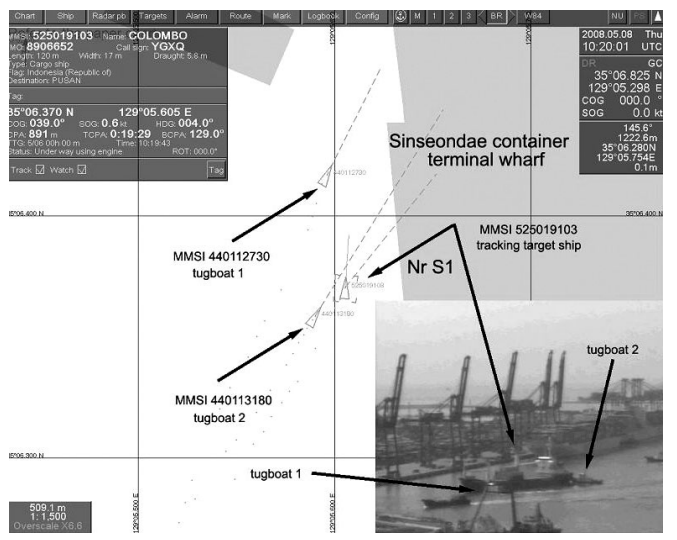

Fig. 9. AIS display and CCTV image for berthing vessel(MMSI 525019103) and two tugboats pushing the port bow and stern of berthing vessel towards the Sinseondae container terminal wharf to be berthed on the eastern face.
한 AIS 심볼의 gyro compass 선수방위(HDT) 를 볼 때, 입항선의 선수미선은 부두와 평행한 상태로 서 부두에 진입하고 있음을 알 수 있다. 또한, 입 항선 의 COG와 예선 1(MMSI 440112730) 및 예선 2(MMSI440113180)의 COG 가 서로 평행하게 약 $40^{\circ}$ 를 유지 하면서 부두를 향해 근접해 가는 상태 로부터 이들 예선 은 입항선을 $\mathrm{COG} 40^{\circ}$ 방향으로 pushing 하고 있음을 알 수 있고, 이와 같은 동적 거동은 고성능 $\mathrm{CCTV}$ camera로부터 실시간으로 모니터링되는 동영 상 정보와 정확하게 일치하고 있음을 알 수 있다. 즉, AIS 및 CCTV 카메라시스 템으로부터 제공되는 각종 정보를 정량적으로 수 집, 분석 및 평가하면 안벽 이나 부두 접이안선박 의 동적거동 상황을 실시간으로 퐈악할 수 있음 을 알 수 있다. 특히, DGPS 에 의한 $\mathrm{COG}$ 정보는 안테 나의 이동방향에 관한 방위 정보를 제공하기 때문에 접이안 선박과 예선(tugboat) 상호간의 동 적인 이동상황을 파악하는데 매우 유호하게 활용 할 수 있음을알수 있었다.

한편, 우리나라에서는 항만의 매 우 협 소한 영 역 내에서 전개되는 선 박의 동적거 동 상황을 실 시간으로 감시함과 아울러 안전한 도선관리 및 호율적인 접 이안 작업을 지 원할 목적으로 2004

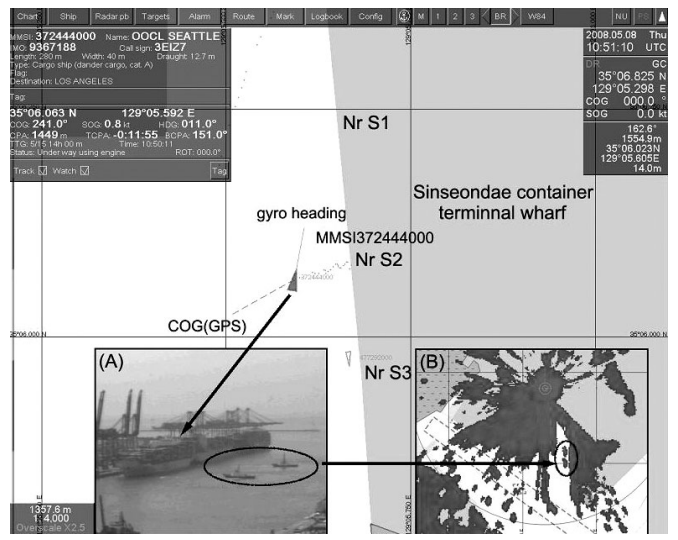

Fig. 10. ARPA radar and CCTV images for the deberthing vessel being assisted out of the pier by two tugboats from Sinseondae container terminal wharf and its tugboats towing the deberthing vessel that was berthed starboard side alongside to the eastern face of the pier. 
년에 선 박설비규정(제 108 조 5 항)을 개 정하여 연 해 구역 이상을 항행하는 총톤수 50 톤 이상의 예 선, 유조선 및 위험물운송선에 선박자동식별장 치(AIS)를 의무적으로 설치하도록 하였다. 그려 나, Fig. 10 에서 조사대상선 박(MMSI 372444000) 의 이안작업에 투입된 두 척의 예선으로부터는 AIS 의 VDL message 가 수신되고 있지 않는 점으 로부터 이들 선박은 AIS 를 작동시키고 있지 않 거나, 또는 AIS 를 탑재하고 있지 않을 가능성이 있다 이와같은 상황하에서 접이안 사고가 발생 하는 경우, 도선사, 선장 및 예선 사이에 책임소 재의 규명이 어렵기 때 문에 항내에서 접이안 작 업에 종사하는 총톤수 50 톤 이상의 모든 예선에 대한 AIS 탑재의무 준수여부를 철저하게 점검 하여 항내에서 선박 안전사고를 미 연에 방지하 기 위한 예 방적인 조치를 강구할 필 요가 있다고 퐌단된 다.

특히, Fig. 10 에서는 AIS 의 VDL message가 수 신되고 있지 않은 관계로 부득히 ARPA radar 와 CCTV camera 등에 의한 정보를 토대로 이안선 과 예선의 동적거 동관계를 퐈악하였다. Fig. 10 에서 신선대 콘테이너 터미널부두 $\mathrm{Nr}-\mathrm{S} 2$ 에서 이안하는 선박의 경우, gyro heading(HDT)은 $11^{\circ}, \mathrm{GPS}$ heading(COG) 은 $241^{\circ}$ 로써 이들 사이에 $230^{\circ}$ 의 차이가 발생하고 있고, 안벽으로부터 이 안되고 있는 선박의 이동계적의 방향이 GPS에 의한 $\mathrm{COG}$ 와 일치하고 있다. 즉, $\mathrm{GPS}$ 의 $\mathrm{COG}$ 는 각 수ㄱㅏㅏㅇㅔ 측정된 위치정보를 토대로 GPS 안테 나의 이동방향을 나타내 는 정 보이므로, 선 박이 정 선수 방위선을 따라 항주하는 경 우에 는 안테 나 이 동궤 적의 방향과 gyro compass 의 선수방위 가 거의 일치하지만, 만일 선 박이 정선수방위 이 외 의 방향으로 움직일 때에는 HDT 와 $\mathrm{COG}$ 가 서 로 일치하지 않는 현상이 발생한다. 따라서, 안 벽이나 부두에 접이안할 때, 해 당선 박의 GPS 에 의한 $\mathrm{COG}$ 를 실시간으로 모니터 링하면 선박이 접안, 또는 이안되는 방위를 원 격지에서 파악할 수 있음을 알 수 있다.
부산 북항에 서와 같이 선 박의 통항량이 폭주 하는 항만에서는 입 출항시 선박의 충돌사고나 접이안시 선박과 부두 구조물 사이의 충돌사고 가 발생하면 인적 및 물적 피해는 물론 해양오염 사고까지 유발되어 심각한 사회문제를 초래한 다. 이 때문에 항만 및 항계 내에서의 선박의 안 전 과 항만의 기능을 원 활하게 유지, 관리하기 위 해서 세 계 각국에 서는 PSC(port state control) 및 VTS 제도를 도입하여 운용하고 있다. 여기서 $\mathrm{PSC}$ 는 선박의 각종설비와 선 원의 자질 등에 관 한 사항을 사전에 점검하여 선박의 안전과 해양 오염사고를 미연에 방지코자 하는 예방적인 선 박안전관리제도인 반면, VTS 는 각종 첨 단정보 수집시스템을 활용하여 직 접 선박의 통항을 감 시 및 관리하면서 안전항행에 필요한 정보를 각 선 박에 제 공하는 실 시간 해 상교통안전관리제 도 이다. 우리나라에서는 1993년 포항항을 시작으 로 여 쉬광양항, 울산항, 마산진해항, 인 천/평 택 항, 대산항, 부산항, 목포항, 군산항, 동해항, 제 주항, 완도항, 부산 신항 등 전 국 13 개 항만에 설 치가 완료되어 운영되고 있다. 그러나, 현재 우 리나라의 경우, VTS 시스템에 의해 실 시간으로 수집되는 정보를 이용하여 출입항 선박의 통항 관리업무 등을 수행할 때, VTS 운용자가 어뗜 정보를 언제 어떻게 어떤 수단을 통해 관제대상 선박에 제공하여 항로에서의 통항효율의 향상 과 안전한 부두 접이안 등을 유도, 제어 및 관리 할 것인가는 자의적 판단에 의해 결 정하는 사려 가 많다. 이 때 문에 항만내 에서 관제사고가 발생 하였을 때, 이해 당사자 사이의 책 임소재 유무에 관한 상황을 명확하게 평가, 분석 및 진단하는 데 많은 어려움이 수반되 고 있어 보다 정 량적인 데이터 수집, 처리 및 평가기법 등에 관한 연구 가 절실하게 요구되고 있는 실정이다. 이 점에서 본 연구의 성 과는 향후 항만 내에서 부두 접이안 과 입출항 선박 등의 항만관제에 필요한 각종 동 적 거동정보를 실시간으로 모니터 링함과 동시에 해 당 정보의 정 량적 분석 및 평 가를 통해 준법운 
항에 관한법 적 판단기 준 등을 제시하는 데 크게 기여할 것으로 판단된 다. 또한, 향후 본 대학이 보유한 VTS 시스템을 활용한 첨단 maritime surveillance system 을 구축하여 우리나라 연 안역 에 대한 어선의 원격조입관리시스템의 구축 및 운용을 위한 연구를 수행하고자 한다.

\section{결 론}

본 연구에서는 부경대학교 용당 캠퍼스에 설 치, 운용되고 있는 항만관제시스템(VTS)을 이 용하여 부산 북항을 입 출항하는 선 박을 대상으 로 항만관제수역에 진입하는 시점부터 부두에 접안이 종료될 때까지의 모든 통항상황과 부두 로부터 이안하는 선박의 모든 동적거 동을 실시 간으로 모니터 링하면서 효율적인 관제에 필요 한 각종 정보를 수집, 분석하였다. 특히, 접이안 선 박과 이 작업을 보조하는 예선에 대한 $\mathrm{ARPA}$ 레이더와 AIS 시스템에 의한 해당선박의 추적 정보, $\mathrm{CCTV}$ 카메라 시스템에 의한 선 박영 상의 모니터링 정보 등을 정 량적으로 수집, 평가 및 분석함으로써 만일에 있을 접이안시의 선박사 고에 대한 이해 당사자 사이의 책임한계를 명확 하게 평가, 진단하기 위한 기법 및 실제적인 모 니터링 사례를 제시하였다. 또한 부산 북항에서 와 같이 교통량이 폭주하는 항만에 있어서 VTS 시스템을 이용하여 출입항 선박의 통항관리업 무를 수행할 때, VTS 운용자가 항로에서의 통항 호율의 향상과 안전한 부두 접이안을 유도 및 제 어하는데 필요한 기초적인 정보의 처리기법 등 을 정 량적으로 제시하였다는 점에서 향후 통항 선박의 관제 및 부두 접이안 선박의 안전성 제 고 등에 크게 기여할 것으로 판단된다. 향후 이 연
구를토대로 본 대학이 보유한 VTS 시스템을 기 반으로 우리나라 연안역에 대한 어 선의 원격조 업관리시스템의 구축 및 운용을 위한 보다 과학 적인 연 구를 수행하고자 한다.

\section{참고문헌}

Kitade, T. and Y. Isamu, 2009. Harbor surveillance radar/camera system. private communication, 1 - 6 .

L - 3 Communications(Klein Associates, Inc.), 2008. Integrated waterside surveillance and security system(IWSSS, HarborGuard), - Performance tests results $-.1-8$.

Nauticast, 2004. AIS(X - Pack DS) installation manual(version 1.0). 24 - 25.

Oda, H., S. Horie, N. Hamamoto, M. Uchida and T. Nagai, 2004. New berthing support system with starfire DGPS. The 2004 International symposium on GNSS/GPS, 1 - 14.

Thoresen, C.A., 2002. Port designer's handbook, Recommendations and guidelines -. Thomas Telford, $95-110$.

Yang, S.Y., K.H. Sohn, H.Y. Lee, M.K. Ha, H.S. Kim, J.H. Lee and N.K. Im, 2004. A study on development of ship manoeuvring simulator for berthing/deberthing. Proceedings of the Annual Autumn Meeting, SNAK, 57 - 62.

Yoon, J.D., H.Y. Jong and C.K. Lee, 2007. A study on the method of conducting a large container vessel safely to the newly built container pier to get alongside in Busan Harbour. Journal of the Korean Society of Marine Environment \& Safety, 13(2), $147-153$.

2009 년 7 월 16 일 접수

2009 년 8 월 9 일 1 차 수정

2009 년 8 월 11 일 수리 